\title{
Fetal Renal Obstruction is Early Detected during Pregnancy by Ultrasonography at Urban Hospital (Naraynganj)
}

\author{
Ahmed $\mathrm{P}^{1}$, Ishaque $\mathrm{A}^{2}$, Ishaque $\mathrm{T}^{3}$, Yeasmin $\mathrm{M}^{4}$, Islam $\mathrm{M} \mathrm{AKM}^{5}$
}

\begin{abstract}
Over the last 3years (September 2012 to September 2015) for the period of 36 months after searching of all gravid uterus ultrasonography report only 40 patients having hydronephrosis detected during antenatal checkup both Naraynganj General Hospital Radiology and Imaging department and Private Clinic, primary finding is oligo hydraminos between 10 weeks to 16 weeks of gestation. All the patients of our study population were subjected to imaging by ultrasonography. This was a prospective study. Out of 40 fetus hydronephrosis were graded according to sonographic grading system. There were two fetus of grade 0, eight fetus of grade-1, eleven fetus grade-2, are nineteen fetus of grade 3 hydronephrosis on advance pregnancy.
\end{abstract}

1. Corresponding Author: Dr. Parveen Ahmed Senior Consultant, Department of Gyn and Obs Narayangong General Hospital

2. Dr. Abu Ishaque Professor, Department of Radiology and Imagining Dhaka Shishu Hospital, Bangladesh Institute of Child Health.

3. Dr. Tanveen Isaque M. S Student, Department of Epidemiology John Hopkins University, USA.

4. Dr. Murshida Yeasmin MBBS, MPH, DCH

Medical Officer, Paediatrics Department 100 Bedded Maternal and Child Hospital Mohammadpur, Dhaka

5. A.K.M Mazharul Islam MBBS, MD (Internal Medicine) Senior Consultant Medicine 250 Bedded Hospital, Patuakhali.

\section{Introduction}

Hydronephrosis is an aseptic dilatation of the whole or part of the kidney due to a partial or intermittent obstruction to the outflow of urine ${ }^{1}$. The term hydronephrosis was first described by Rayer in $1842^{2}$. It is derived from three parts each has its own meaning "Hydro" stands for water. "Nephrosis" stands for kidney and "osis" means condition ${ }^{3}$. Hydronephrosis is a well known and common pathological condition in fetus presenting with oligo hydraminos with the increasing use of fetal ultrasonography hydronephrosis are detected before symptoms to develop are signs of renal mass become apparent. Among the hydronephrosis, pelvic ureter junction anomaly is the cause of $40 \%$ foetal hydronephrosis with an incidence of in 1250 birth $^{4}$. Bilateral obstruction is present in $5 \%$ to $10 \%$ of cases, detected at mid and late pregnancy 5 .

\section{Materials and Methods}

Prospective study done on special group of patient having oligo hydronephrosis intra uterian growth retardation, mal-presentation in antenatal checkup. As sexes are detected easily 24 weeks to 30 weeks of gestation, female fetus having single pelvic ureter junction obstruction either left or Right, however, bilateral hydronephrosis is more commence on male fetus due to bladder outlet obstruction such as posterior urethral valve.

A 3.5 MHz curvilinear transducer is routinely used. No preparation is required only patient should be in full bladder in early pregnancy, patients are in supine position and transducer placed transverse and longitudinally, fetal liver serves as an acoustic window for imaging of the Right kidney. Fetal stomach and spleen as an acoustic window for imaging of the left kidney. A patient are selected those amniotic fluid index are less than normal and intra uterian growth retardation.

\section{Result}

Bilateral hydronephrosis was higher than unilateral hydronephrosis; cause of bilateral hydronephrosis was posterior urethral valve which is more common. Valve is not detected by ultrasonography during pregnancy even after birth. It should be detected by other radiological procedure like micturation cystourography after birth. Usually pelvic ureter junction obstruction is commonly unilateral and on left side.

Table-I: Ultrasonography demonstrates and measures the degree of pelvis dilatation ${ }^{6}$.

\begin{tabular}{ccc}
\hline Grade & $\begin{array}{c}\text { Size of Renal } \\
\text { pelvis }\end{array}$ & Calyceal dilatation \\
\hline i & $<10 \mathrm{~mm}$ & Physiological \\
ii & $10-15 \mathrm{~mm}$ & Normal calyces \\
iii & $>15 \mathrm{~mm}$ & Slight dilatation \\
iv & $>15 \mathrm{~mm}-20 \mathrm{~mm}$ & Moderate dilatation \\
V & $>20 \mathrm{~mm}$ & Sever dilatation \\
\hline
\end{tabular}


Less than $10 \mathrm{~mm}$ size of renal pelvis was grade- $i$ (physiological) $10 \mathrm{~mm}$ to $15 \mathrm{~mm}$ of renal pelvis was gradeii (normal calyces) higher than $15 \mathrm{~mm}$ was grade-iii and iv (slight dilatation and moderate dilatation) and higher than $20 \mathrm{~mm}$ size of renal pelvis was grade-v (sever dilatation). Mild pelviectasis (defined mild fetal renal pelvis dilatation) measuring renal pelvis antero posterior diameter of $4 \mathrm{~mm}$ or greater at 15 to 20 weeks, $5 \mathrm{~mm}$ of greater between 20 and 30 weeks and $7 \mathrm{~mm}$ or greater between 30 and 40 weeks) $)^{7}$

Hydronephrosis is identified as separation of the walls of the collecting system by fluid urine ultrasound grading system of hydronephrosis ${ }^{8}$.

Table- II: Hydronephrosis of 40 patients (our study population).

\begin{tabular}{ccc}
\hline Grade & No of Patient & Percentage \% \\
\hline Grade 0 & 2 & 5 \\
Grade 1 & 8 & 20 \\
Grade 2 & 11 & 27.5 \\
Grade 3 & 19 & 47.5 \\
\hline & 40 & 100
\end{tabular}

Grade-0 Homogenous central renal sinus complex without separation.

Grade-1 Separation of central sinus echoes of ovoid configuration continuous echogenic sinus periphery. 52\% predictive valve for obstruction.

Grade-2 Separation of central sinus echoes of rounded configuration, dilated calcyces connecting with renal pelvis, continuity of echogenic sinus periphery.

Grade-3 Replacement of major portion of renal sinus, discontinuity of echogenic sinus periphery.

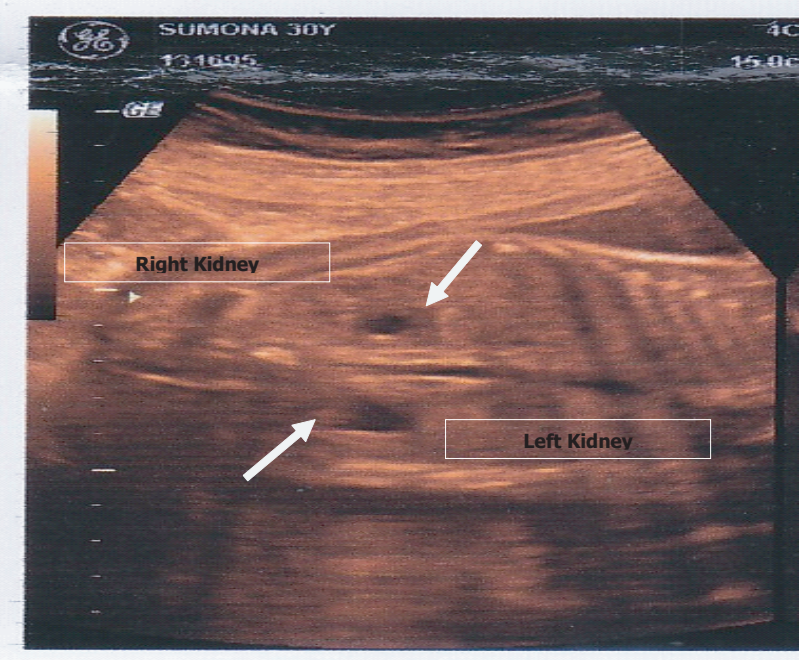

Fig - I : Longitudinal ultrasonography scan of 34 weeks gravid uterus shows sonolucent area (Black Spot) is dilated renal pelvis over both kidney

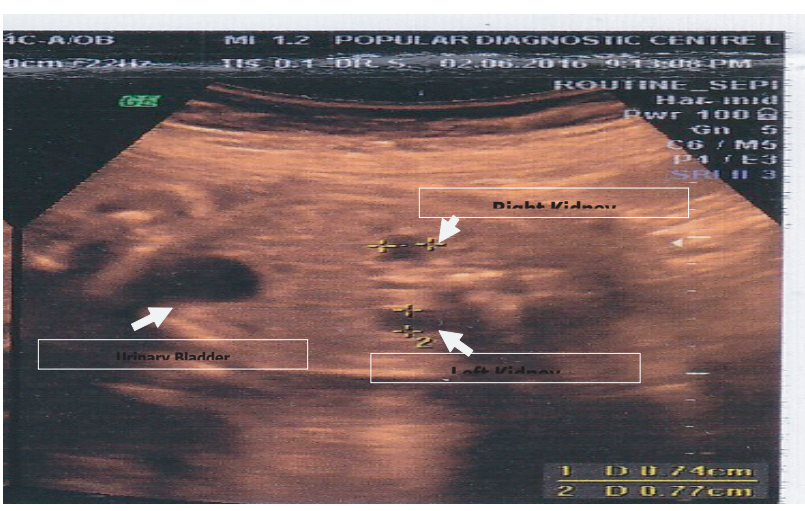

Fig - II: Same patient of figure 01 with transverse scan sonolucent area (Black Spot) diameter is right is $7.4 \mathrm{~mm}$ and left is $7.7 \mathrm{~mm}$. Mild dilated both renal pelvis

\section{Discussion}

Ultrasonography plays a crucial role in the evolution of the fetal urinary tract by detecting, locating and characterizing the severity of anomalies in an attempt to predict prognoses and to optimize prenatal management ${ }^{8}$. Antenatal check up ultrasonography has become the most commonly performed examination for evaluating the urinary tract ${ }^{9}$. This is a because of its speed and safety, relatively low cost, wide spread availability, non invasiveness and lack of ionizing radiation and high accuracy in identifying anatomical abnormalities, dilatation of renal pelvis. Pelvic ureter junction obstruction producing unilateral hydronephrosis involves the left kidney (two third) ${ }^{10}$. In our study out of seven pelvic ureter junction obstruction hydronephrosis, six $(85.7 \%)$ fetus presented with left side hydronephrosis. Ultrasonography demonstrate and measures the degree of renal pelvic and calcyceal dilatation. Pelvic dilatation less than $12 \mathrm{~mm}$ (anterior-posterior diameter) is considered minimal between 12 and $20 \mathrm{~mm}$ moderate and greater than $20 \mathrm{~mm}$ sever form of pelvic ureter junction obstruction. Intra uterian ultrasonography can also show important negative sign, such as absence of dilatation of ureters.

The study performed on basis of fetal renal pelvis and oligohydrominos. Amniotic fluid measure about $50 \mathrm{ml}$ at $12 \mathrm{wks}, 400 \mathrm{ml}$ at $20 \mathrm{wks}$ and $1000 \mathrm{ml}$ at peek (36 to $38 \mathrm{wks}$ ). Our study is based on amount of fluid as well as by amniotic fluid index. Clinically uterus size is smaller than period of amenorrhea. Less fetal movement, uterus is full of fetus evidence of intra uterian growth retardation (IUGR) and mal-presentation (breech).

There are so many causes of oligohydraminos like fetal chromosomal anomalies, intra uterian infection, drug, renal agenesis and obstruction of the urinary tract like pelvic ureter junction or posterior urethral valve. In our study grade-3 hydronephrosis was 19 (47.5\%). This represented greater number of patient with severe hydronephrosis. This was due to delayed referral from primary and secondary health care centre or lack of health awareness $11(27.5 \%)$ patient was of grade- 2 
hydronephrosis. This represented moderate to severity of the disease in almost $1 / 4$ of the study population. There were 9 patients of grade- 1 hydronephrosis. The rest 2 (5\%) were of grade- 0 hydronephrosis. This gives an excellent diagnostic value of antenatal check up ultrasonography, early detection of fetal hydronephrosis by the modern imaging technique. Specially 3D/4D ultrasonography would be able to salvage most of the kidney, when intra uterian hydronephrosis is diagnosed a post partum sonogram and other radiological imaging model is indicated to confirm the diagnosis.

\section{References}

1. Tiptaft R.C. The kidneys and Ureters. In: Baily and Love's short practical of surgery. $21^{\text {st }}$ edition. ELS; 1991: 31.

2. Charies M.M, Dick G. Ureters pelvic junction obstruction. In: Asheraft KW, eds. Pediatric Surgery $2^{\text {nd }}$ ed. Sanders Company ;1993: 582-587.

3. Tabers cycllo pedic medical diction any PUB-System. $17^{\text {th }}$ ed. 925 .
4. Mouriquarl P. Congenital anomalies of pyelo urethral junction and the uretes. Pediatric surgery. $5^{\text {th }}$ ed. 15911604.

5. Willian DL, Kenawl M. M, Synder, HMIII Lebowitz RI, Colodny AH. 1980.

6. Callen. Urinary tract dilatation in utero classification and clinical application Radiology. 1986 : 645-647.

7. Callen. Ultrasound evaluation of the fetal genito-urinary system, ultrasonography in obstetrics and gynecology. $3^{\text {rd }}$ ed. 399.

8. Mandelli J. Biyth BR. Reters CA. Structural genitourinary defects detected in utero Radiology. 1991:178-193.

9. Rao, Heptin Stall R-H Experimental hydronephrosis investigation urol. 1968;6:188.

10. Tip laft R.C. The kidneys and ureters. In : Baily and love's short practices of surgery. $21^{\text {st }}$ ed. ELKS; 1991: 1331. 